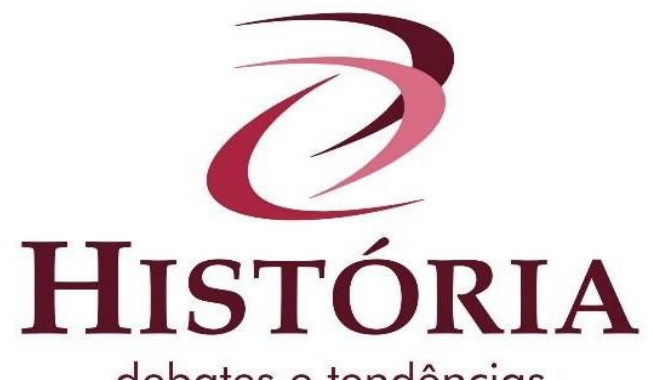

\title{
A educação polonesa na Colônia Erechim: a escola como instrumento de organização e resistência
}

\section{Polish education in Colônia Erechim: school as an instrument of organization and resistence}

\author{
Edukacja polska w kolonii Erechim: szkoła jako instrument organizacji i \\ oporu
}

\author{
Isabel Rosa Gritti ${ }^{\mathrm{i}}$ \\ Silvana Maria Grittii
}

\begin{abstract}
Resumo: Este artigo traz uma análise acerca da educação desenvolvida junto aos grupos de imigrantes poloneses que se estabeleceram na Colônia Erechim, criada em 1908, na zona norte do Rio Grande do Sul. Evidencia-se que a nacionalização do ensino no período do Estado Novo (1937-1945) facilita uma acentuação do preconceito linguístico em desfavor das culturas de origem estrangeira, característica excludente que perpassa a formação do projeto educativo brasileiro e, consequentemente, seu fazer pedagógico. Observa-se que a escola pública que vai sendo construída nesta área de imigração é tingida por estigmas, resistências e tensões diversas. Com a retrospectiva histórica deste processo, conclui-se que o planejamento educativo oficial requer a legitimação da escola necessária ao projeto hegemônico de desenvolvimento da sociedade.
\end{abstract}

Palavras-chave: Colônia Erechim. Conflitos. Educação polonesa. Nacionalização.

\begin{abstract}
This article provides an analysis of the education developed with the groups of Polish immigrants who settled in Colônia Erechim, created in 1908, in the northern zone of Rio Grande do Sul. It appears that the nationalization of Brazilian schools in the period of the Estado Novo (1937-1945) facilitated an accentuation of linguistic prejudice to the detriment of cultures of foreign origin, a form of social exclusion that permeates the Brazilian educational project and, consequently, its pedagogical practice. It is observed that the public school that was being built in this area of immigration was colored by different stigmas, resistances and tensions. With the historical perspective of this process, it is concluded that the official educational planning needed to legitimate the scholar principles of the hegemonic project of national development.
\end{abstract}

Keywords: Colonia Erechim. Social conflicts. Polish education. Nationalization.

Streszczenie: Artykuł dotyczy edukacji opracowanej z grupami polskich imigrantów w Kolonii Erechim, utworzonej w 1908 roku w południowej Brazylii. Tekst akcentuje rolę polskiego imigranta jako podmiotu społecznego, który stara się budować swoją przestrzeń bytu w kontekście konfrontacji i przeciwności wynikających z polityki nacjonalizacyjnej w brazylijskim systemie edukacji. W tej sytuacji szkoły zaczęły niejako promieniować procesami oporu, konfliktami i napięciami.

Słowa kluczowe: Kolonia Erechim. Konflikty społeczne. Polska edukacja. Nacjonalizacja. 


\section{A Colônia Erechim}

Uma retrospectiva histórica da Colônia Erechim, desde sua fundação em 1908, visibiliza as relações do projeto de desenvolvimento capitalista articulado a partir da construção da ferrovia, elemento que foi fundamental para o desenvolvimento da Colônia. A estrada de ferro São Paulo-Rio Grande chegou à nova colônia em 1910, e até o Rio Uruguai, limítrofe ao Estado de Santa Catarina, em 1911. A ferrovia possibilitou a chegada dos imigrantes europeus e seus descendentes, e foi fundamental no transporte da produção, o que contribuiu para o rápido desenvolvimento da Colônia. Nesse sentido, Jean Roche nos diz que Erechim ficará,

pelo menos, como um dos exemplos mais significativos de impulso demográfico que se deve à colonização. É verdade que esta se realizou ao longo da via férrea Santa Maria-São Paulo, o que lhe permitiu escoar imediatamente os produtos agrícolas com facilidade excepcional na história das Colônias riograndenses (ROCHE, 1969, p. 281).

A sede da Colônia Erechim situava-se, desde sua criação, no povoado que mais tarde seria o Município de Getúlio Vargas, sendo transferida em 1915 para Paiol Grande. No ano de 1918, o grande distrito Colônia Erechim se emancipava de Passo Fundo, passando a ser o Município de Erechim. A área total da então Colônia Erechim aparece exposta no mapa abaixo, com os nomes de suas subdivisões, atualmente municípios independentes, também emancipados ao longo do século XX. Hoje, a área de Erechim corresponde somente àquela da antiga sede de Paiol Grande.

A nova colônia teve a presença de dois agentes colonizadores: o Estado brasileiro, e as Companhias Privadas de Imigração e Colonização, notadamente a Jewish Colonization Association (ICA) e a Luce e Rosa. Estes agentes foram os responsáveis pela vinda e assentamento dos colonos: imigrantes europeus, em menor número, e descendentes de imigrantes ou reimigrantes, ${ }^{\text {iii }}$ em maior número. Estes últimos se deslocaram das chamadas "colônias velhas", as primeiras criadas no Rio Grande do Sul, e vinham em busca de mais e melhores áreas de terras. No caso dos imigrantes poloneses e seus descendentes, esse sonho não se concretizou: acabaram adquirindo somente meio lote de terra e nas áreas mais acidentadas da Colônia Erechim. 
Figura 1. Mapa atual da Região correspondente à antiga Colônia Erechim.

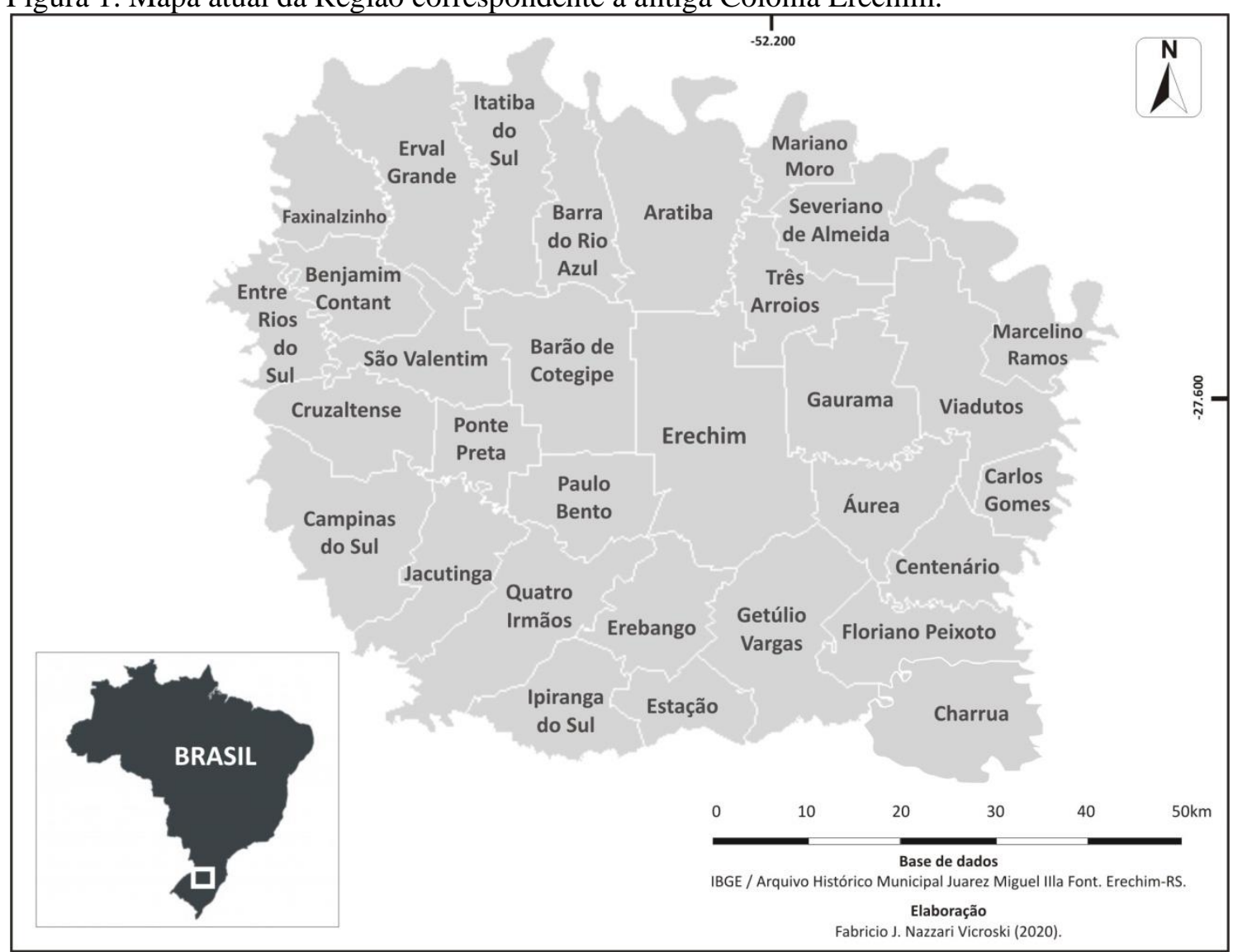

Fonte: Base de dados do Arquivo Histórico Municipal Juarez Miguel IIla Font. Erechim/RS.

O Diretor do Departamento de Terras e Colonização, da Secretaria de Obras Públicas, Terras e Colonização, do Estado do Rio Grande do Sul, o engenheiro Carlos Torres Gonçalves foi o grande defensor da criação da Colônia Erechim. Argumentava que as colônias sul-riograndenses Ijuí e Guarani haviam esgotado a possibilidade de novos assentamentos, e que a fertilidade das terras e a grande procura por particulares, que aqui estavam se instalando de forma desordenada, exigiam a regularização das terras, o que acabou acontecendo em 1908 com a fundação da Colônia. Esta, por sua vez, seria a última colônia a ser criada no Estado e pelo Estado, cuidadosamente planejada pelo positivista gaúcho Carlos Torres Gonçalves.

O planejamento da Colônia tinha em vista impedir a possível insatisfação, os movimentos de rebeldia e contestação e o consequente abandono da mesma por parte dos imigrantes. Estes fatores foram comuns nos demais núcleos coloniais em que os colonos poloneses foram instalados. Nesse sentido, Carlos Torres Gonçalves obteve pleno sucesso. A instalação dos imigrantes europeus e descendentes na Colônia Erechim, apesar de sua diversidade étnica e cultural foi tranquila, sem maiores conflitos. O diretor da mesma, Severiano de Souza e Almeida, é quem testemunha, em 4 de março de 1912:

Confirmando o meu telegrama de 1 do corrente a V. Excia, o Sr. Dr. Secretário, 
em resposta a um que recebi sobre a imaginária saída de imigrantes para a República Argentina, cumpre-me levar ao vosso conhecimento que semelhante notícia não tem fundamento algum, pois os imigrantes em geral, quer do povoamento, quer espontâneos, acham-se muito satisfeitos e entusiasmados aqui, os quais, de modo algum pretendem retirar-se da Colônia, de que, é um testemunho o fato de a maioria deles ter feito chamada de parentes, cujos pedidos tenho dirigido ao Inspetor de Povoamento nessa capital, para o devido encaminhamento dos mesmos a esta Colônia, de forma que, procedendo eles assim, não têm naturalmente intenção de retirar- se e, sim, de definitivamente permanecerem nos lotes em que se estabeleceram. ${ }^{\text {iv }}$

Se a chegada e o assentamento dos imigrantes das diversas etnias transcorreu com tranquilidade, em relação com a Comissão de Terras responsável pela instalação dos mesmos, ou mesmo entre os diferentes grupos, não podemos afirmar a inexistência de conflitos e tensões ao longo da constituição e da formação social da Colônia Erechim. Conflitos e tensões que se manifestaram em diferentes momentos e diversas situações: na luta pela terra, quando caboclos e indígenas são deslocados, em expressões preconceituosas como "polaco vagabundo", "índio preguiçoso", nas reclamações apresentadas pelos pais em relação aos métodos dos professores, nos conflitos decorrentes da implementação da nacionalização do ensino, entre outros.

No extenso território da nova Colônia, grupos de várias nacionalidades se fizeram presentes. A Comissão de Terras, órgão estatal, era a responsável pela venda dos lotes coloniais e assentamento dos imigrantes, via colonização oficial e, portanto, era responsável pelo registro dos mesmos. Nos livros de registros de entrada de imigrantes correspondentes aos anos de 1911 a 1914, encontramos alemães, austríacos, polacos, russos, italianos, portugueses, suecos, holandeses e dois japoneses. Ao longo do processo de ocupação pelos europeus e/ou descendentes, três grupos étnicos tornaram-se numericamente superiores: italianos, poloneses e alemães. Segundo Juarez Miguel Illa Font (1983), em 1915 havia na Colônia Erechim, segundo cadastro da Comissão de Terras, a composição populacional apresentada na Tabela 1 e Figura 2.

Tabela 1. Total de pessoas por grupos étnicos na Colônia Erechim em 1915.

\begin{tabular}{lcc}
\hline Grupos étnicos & $\mathbf{N}^{\mathbf{0}}$ de pessoas & $\%$ \\
\hline Diversas & 7.683 & 27,6 \\
Brasileiros & 7.114 & 25,5 \\
Poloneses & 5.721 & 20,5 \\
Alemães & 3.652 & 13,1 \\
Italianos & 1.827 & 6,6 \\
Portugueses & 734 & 2,6 \\
Austríacos & 722 & 2,6 \\
Suecos & 240 & 0,9 \\
Espanhóis & 106 & 0,4 \\
Franceses & 74 & 0,3 \\
\hline
\end{tabular}

\section{Total}

27.873

Fonte: Illa Font, 1983, p. 14.

Elaboração das autoras. 
Figura 2. Grupos étnicos residentes na Colônia Erechim em 1915.

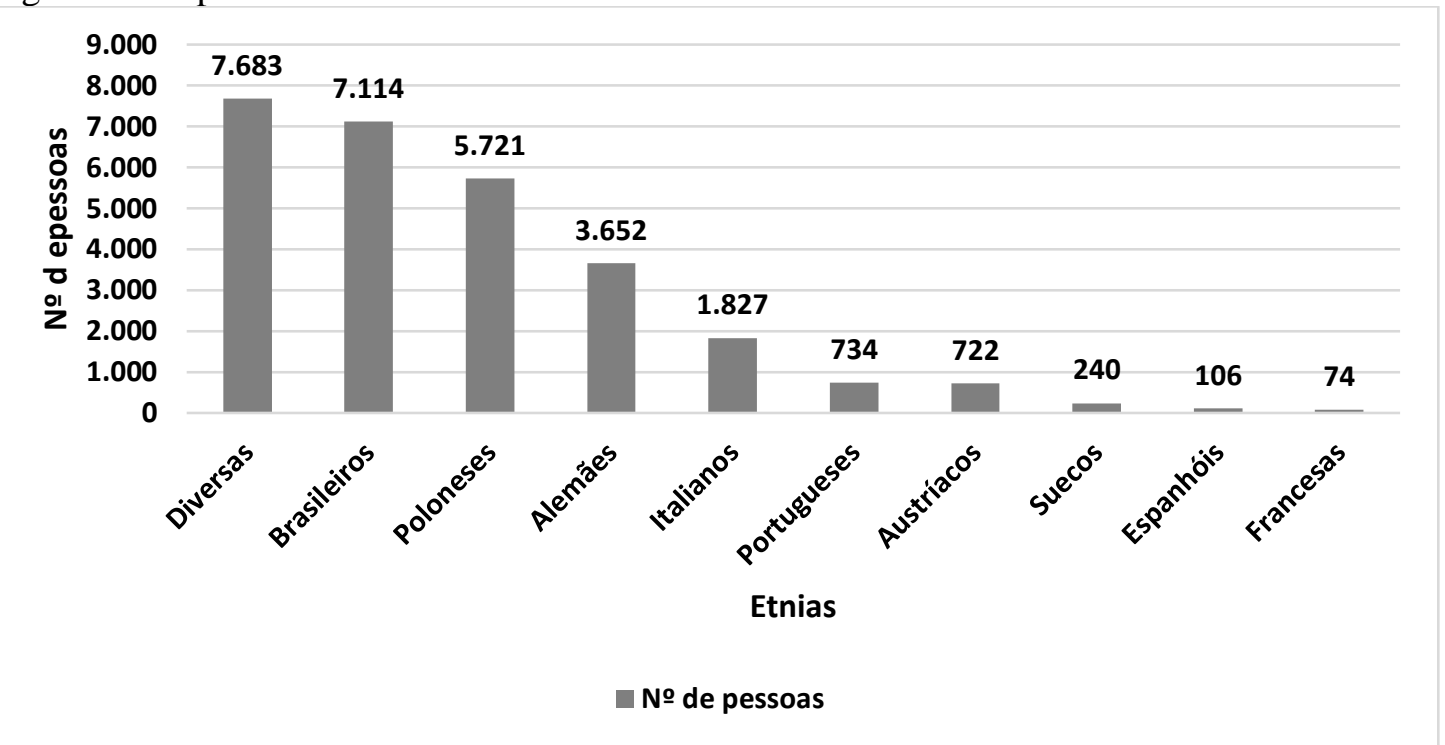

Fonte: Illa Font, 1983, p.14.

Elaboração das autoras.

Não obstante a superioridade numérica de Poloneses, Alemães e Italianos, a Colônia Erechim foi constituída com presença significativa de inúmeros grupos étnicos, como demonstrado acima. Discutindo essa diversidade étnica, Illa Font escreve:

Qualquer dicionário genealógico das famílias do Paiol Grande/Boa Vista englobaria inestimável número de sobrenomes denotando as várias origens étnicas da sociedade que começa a surgir em 1912, revelando a riqueza do processo de caldeamento de setenta anos (ILLA FONT, 1983, p. 15).

No entanto, o caldeamento não se realizou no momento inicial. De início, os grupos coloniais se estabeleceram isoladamente e foram constituindo sua organização social. É de se destacar aqui a instituição escolar, que na sua origem é construída e constituída somente pelos imigrantes. Ela deixa de ser o que era até então: a escola exclusiva de uma etnia, na medida mesmo das políticas governamentais de ocupação e de nacionalização do ensino, formuladas pelo Governo Federal.

Em 1924 é publicada, em formato mimeografado, uma das primeiras obras sobre a presença dos imigrantes e descendentes de poloneses no Brasil. Seu autor, o primeiro Cônsul polonês no Brasil, Kazimierz Głuchowski, nos diz que em 1920 os imigrantes e descendentes poloneses no Brasil correspondiam a 102.596 e se concentravam nos estados sulinos, como mostrado na tabela 2. 
Tabela 2. Número de imigrantes poloneses no Brasil em 1920.

\begin{tabular}{lcc}
\hline & $\mathrm{N}^{\circ}$ de Imigrantes Poloneses & $\%$ \\
\hline Paraná & 42.046 & 41,0 \\
Rio Grande do Sul & 32.300 & 31,5 \\
São Paulo e outros Estados & 21.500 & 21,0 \\
Santa Catarina & 6.750 & 6,6 \\
\hline Total & 102.596 &
\end{tabular}

Figura 3. Número de Imigrantes poloneses no Brasil em 1920.

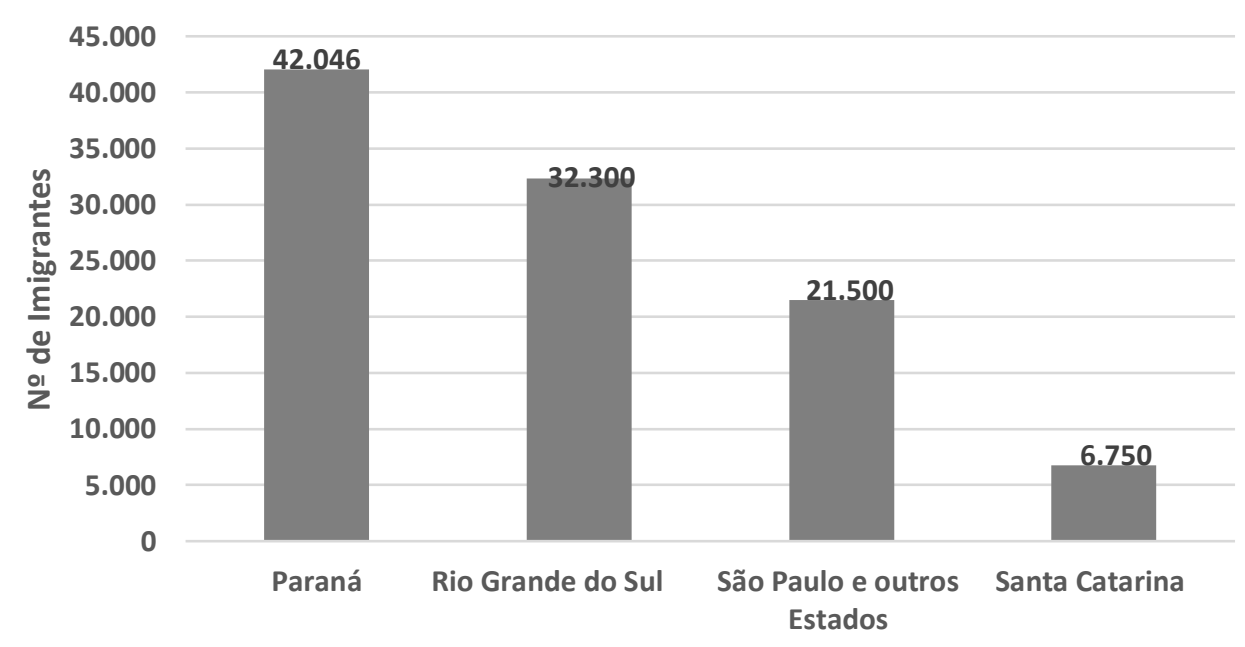

Imigrantes

Fonte: Głuchowski, 2005.

Elaboração das autoras.

Segundo Gardolinski (1958), quatro anos depois são 61.200 os imigrantes e descendentes de poloneses no Rio Grande do Sul, e estavam distribuídos em vários núcleos. Importante destacar que a maior parte dos poloneses no Estado se encontra na Colônia Erechim, sendo em torno de 25.000 dos 61.200. Na Tabela 3 (abaixo), que lista as localidades gaúchas com imigrantes poloneses, estão identificadas com asterisco as pertencentes à Colônia Erechim. 
Tabela 3. Localização dos imigrantes poloneses no Rio Grande do Sul em 1924.

\begin{tabular}{lcc}
\hline LOCALIZAÇÃO & $\begin{array}{c}\text { TOTAL DE } \\
\text { IMIGRANTES }\end{array}$ & \% \\
\hline Rio Grande & 1.200 & 1,96 \\
Pelotas & 300 & 0,49 \\
São Feliciano & 3.600 & 5,88 \\
São Feliciano e arredores & 600 & 0,98 \\
Mariana Pimentel & 1.200 & 1,96 \\
Mariana Pimentel e arredores & 300 & 0,49 \\
São Braz e Camaquã & 300 & 0,49 \\
Porto Alegre & 3.600 & 5,88 \\
São Antônio da Patrulha & 420 & 0,69 \\
Outras localidades na região do litoral & 900 & 1,47 \\
São Marcos & 480 & 0,78 \\
Antônio Prado & 300 & 0,49 \\
Alfredo Chaves & 1.200 & 1,96 \\
Santa Tereza e Bento Gonçalves & 300 & 0,49 \\
Guaporé e São Luiz da Casca & 1.500 & 2,45 \\
Jaguari & 900 & 1,47 \\
Centro do Estado & 900 & 1,47 \\
Erechim* & 1.500 & 2,45 \\
Capoerê* & 1.200 & 1,96 \\
Castilho e Rio dos Índios* & 4.200 & 6,86 \\
Áurea* & 3.600 & 5,88 \\
Rio do Peixe* & 3.000 & 4,90 \\
Caçadores Ligeiro* & 600 & 0,98 \\
Barão* & 3.000 & 4,90 \\
Secção Cravo e arredores* & 600 & 0,98 \\
Baliza* & 1.200 & 1,96 \\
Gaurama* & 3.000 & 4,90 \\
Dourado* & 1.800 & 2,94 \\
Vale do Uruguai de Marcelino Ramos a Iraí* & 2.700 & 4,41 \\
Ijuí & 3.000 & 4,90 \\
Guarani & 12.000 & 19,61 \\
Santa Rosa e arredores & 1.200 & 0,96 \\
Santo Ângelo & 600 & \\
\hline TOTAL & $\mathbf{6 1 . 2 0 0}$ & \\
\hline
\end{tabular}

Fonte: Gardolinski (1958).

*Localidades pertencentes à Colônia Erechim.

Os agrupamentos da antiga Colônia Erechim, marcados com asterisco na Tabela 3, foram gradativamente conquistando sua emancipação política, alterando suas denominações até constituírem o atual território expresso no mapa da Figura 1. Ainda, no interior dos distritos da Colônia - originalmente vilas, posteriormente municípios - os colonos constituíram linhas (pequenas comunidades), onde criavam uma infraestrutura, ainda que mínima, que possibilitasse a socialização, a comunicação e o consequente amparo. Assim, dotaram cada distrito e cada linha com uma igreja, um clube e uma escola. No início da formação da comunidade, a escola, a igreja e o clube funcionavam no mesmo espaço. Esse "tripé social" por assim dizer, foi comum a todos os grupos étnicos, e, portanto, também aos poloneses. Como o objetivo deste texto é discutir a 
constituição da educação dos imigrantes e descendentes de poloneses, e as tensões em torno da mesma, torna-se fundamental visualizar a distribuição das escolas construídas por eles na Colônia Erechim.

\section{Os imigrantes poloneses e a escola}

A organização dos imigrantes poloneses em colônias e linhas decorreu, segundo Gardolinski (1976), da necessidade de sobrevivência. A ausência de políticas públicas que objetivassem criar infraestrutura de apoio aos núcleos de imigrantes impôs sua organização, a partir de suas iniciativas e possibilidades. Para Gardolinski, aprendizados importantes como conviver e organizar-se eram imperativos para a sobrevivência destes grupos. Este imigrante,

aparentemente apático e mal orientado, dispunha - conforme se verificou posteriormente - de consideráveis reservas de energia e de uma verdadeira intuição para congregar-se em comunidades. E, para o imigrante, a razão de sua existência passou a girar em torno da: igreja, sociedade e escola (GARDOLINSKI, 1976, p. 15).

Em relação à educação, a presença do Estado no norte do Rio Grande do Sul, e obviamente na região da Colônia Erechim, veio tardiamente. As escolas foram construídas e assumidas pelos imigrantes. Posteriormente, o Estado assumiria o pagamento do professor, através das subvenções destinadas às escolas dos imigrantes. Porém, no período de 1937 a 1945, no chamado Estado Novo, o braço do Estado atingiu pesadamente essas escolas. Proibiu o ensino da língua materna e o uso da língua materna na sala de aula.

Essa determinação veio provocar inúmeros conflitos entre professores, alunos e comunidade. Entre as denúncias dos pais, encontramos "que a professora não ensinou seus filhos, o que aprenderam nos anos passados esqueceram muitas coisas". "O registro dos conflitos, desencontros, desentendimentos em relação à escola e sua tarefa de ensinar ocorrem e são mais significativos, a partir da retirada da escola "das mãos" dos imigrantes. A contradição existente na atenção oficial dos governantes à educação dos imigrantes se manifesta, notadamente, a partir dos interesses antagônicos entre imigrantes e governo nacional.

Na década de 1950, os imigrantes colonos ainda assumiam a criação e administração das escolas, nas regiões interioranas do Rio Grande do Sul, mas a sua construção física passa a ser de responsabilidade do Município ou do Estado, bem como o projeto educativo aí desenvolvido. Assim, temos que, no dia 16 de novembro de 1952, em Lajeado Bonito, Distrito de Carlos Gomes, um grupo de agricultores contando com a presença do subintendente funda uma associação com o objetivo de negociar, junto ao Município de Erechim, a construção de uma escola para atender 42 
alunos. Após a construção da mesma, o proprietário do lote onde a escola será construída, fará a doação do mesmo ao Município. ${ }^{\text {vi }}$ Desta forma o poder público, seja o Município ou o Estado, começa a se fazer presente na administração da educação no interior do Rio Grande do Sul, notadamente na região da Colônia Erechim, último território a contar com a presença pública no campo educacional.

Kazimierz Głuchowski, o citado Cônsul Polonês, diz que em 1920 "a enorme colônia de Erechim dispunha apenas de algumas escolinhas que vegetavam miseravelmente" (GLUCHOSWSKI, 2005, p. 143). Contudo, o mesmo Cônsul descreve uma realidade bem diferente em 1924: nesse ano, já haviam sido fundadas na Colônia Erechim 15 escolas polonesas, duas das quais estão inativas. A Figura 4 e a Tabela 4 apresentam a relação completa dessas treze (13) escolas ativas, sendo que duas destas foram fundadas em Rio do Peixe, atual Município de Carlos Gomes, e uma em 1915 em Floresta, atual Município de Barão de Cotegipe. As demais foram criadas em 1919, 1920 e 1922. No ano de 1924, trezentos e oitenta e sete (387) imigrantes poloneses e descendentes frequentavam as escolas.

Todas essas treze escolas eram filiadas à União das Sociedades Educacionais Polonesas Cultura. Kultura e Oświata eram duas sociedades que agregavam as escolas polonesas do Brasil, particularmente dos três Estados sulinos. A diferença entre elas era basicamente religiosa. Enquanto as escolas filiadas à Kultura eram leigas e o ensino religioso era opcional para a escola, as pertencentes à União das Escolas Católicas Polonesas Oświata (Educação) entendiam ser necessário ministrar ensino religioso na escola, e este ficava a cargo dos sacerdotes (SILVA; TRINDADE, 2017).

Figura 4. Escolas polonesas na Colônia Erechim por localidade até 1924.

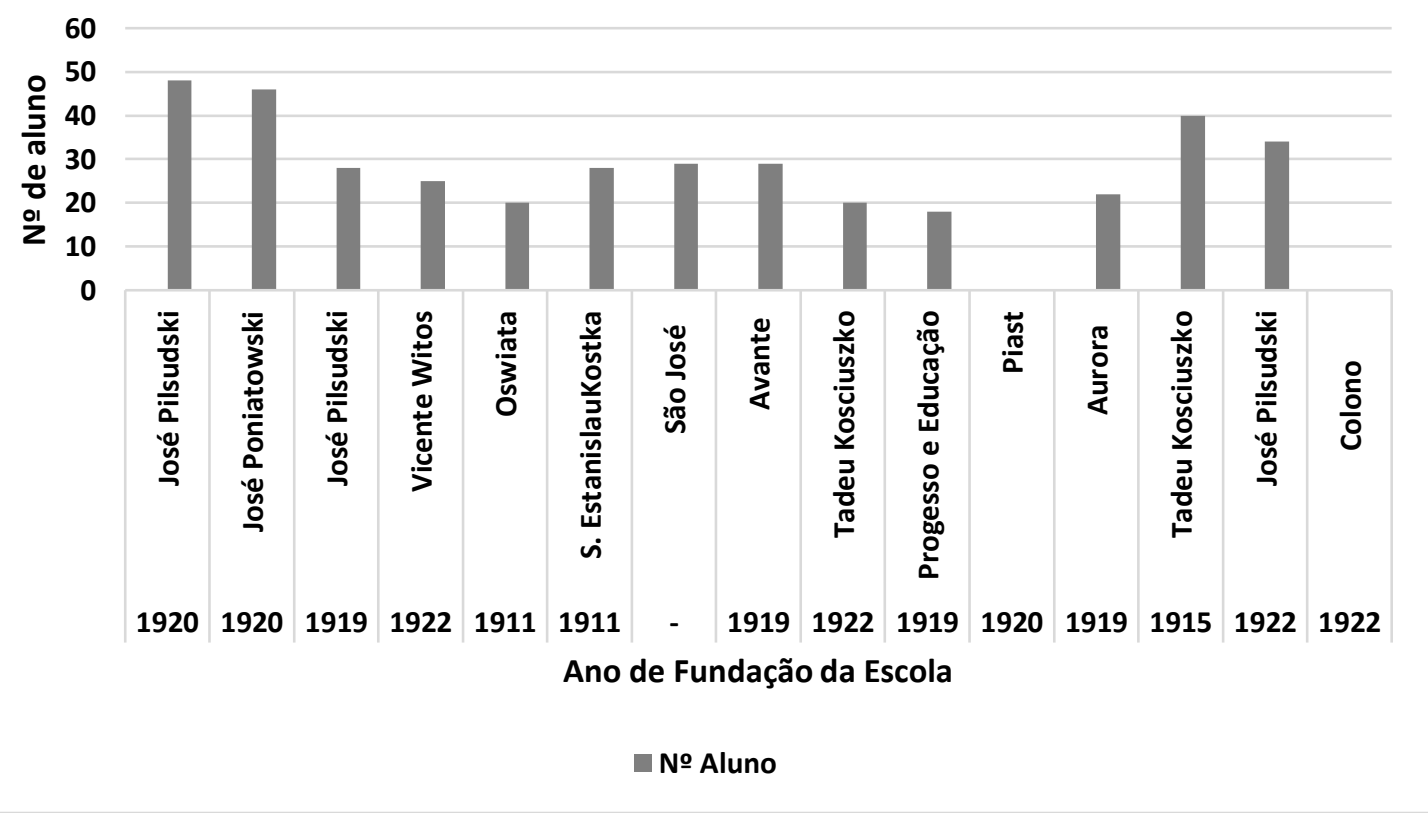

Fonte: Głuchowski, 2005.

Elaboração das autoras. 
Tabela 4. Escolas polonesas na Colônia Erechim por localidade até 1924.

\begin{tabular}{llllccc}
\hline \multicolumn{1}{c}{ Escola } & Município & Localidade & Fundação & No $^{\mathbf{0}}$ Alunos & \% \\
\hline 1 & José Pilsudski & Erechim & Barro & 1920 & 48 & 12,4 \\
2 & José Poniatowski & Erechim & Treze de Maio & 1920 & 46 & 11,9 \\
3 & José Pilsudski & Erechim & Km 13 & 1919 & 28 & 7,2 \\
4 & Vicente Witos & Erechim & Guaporé & 1922 & 25 & 6,5 \\
5 & Oświata & Erechim & Rio do Peixe & 1911 & 20 & 5,2 \\
6 & S. Estanislau Kostka & Erechim & Rio do Peixe & 1911 & 28 & 7,2 \\
7 & José & Erechim & Lageado Israel & - & 29 & 7,5 \\
8 & Avante & Erechim & Caçador & 1919 & 29 & 7,5 \\
9 & Tadeu Kosciuszko & Erechim & Baliza & 1922 & 20 & 5,2 \\
10 & Progresso e Educação & Erechim & Dourado & 1919 & 18 & 4,7 \\
11 & Piast & Erechim & Dourado & 1920 & n.d. & - \\
12 & Aurora & Erechim & Dourado & 1919 & 22 & 5,7 \\
13 & Tadeu Kosciuszko & Erechim & Floresta & 1915 & 40 & 10,3 \\
14 & José Pilsudski & Erechim & Três Vendas & 1922 & 34 & 8,8 \\
15 & Colono & Erechim & Boa Vista & 1922 & n.d. & - \\
\hline & TOTAL & & & & 387 & \\
\hline
\end{tabular}

Fonte: Głuchowski, 2005.

Legenda: nd (não disponível.) - Escola fechada.

Todas as treze (13) escolas em atividade na região da Colônia Erechim em 1924 foram criadas e organizadas pelos imigrantes. Eles custeavam as despesas com o professor e as despesas da escola. Segundo dados do Cônsul Głuchowski, o custo médio por aluno era de 1,5 contos de réis. Em apenas três delas, o custo era um pouco mais elevado: 2,5 contos de réis. Na quase totalidade das escolas, o patrimônio da mesma pertencia à Sociedade Escolar; nas demais, o patrimônio pertencia à capela.

Apesar de uma das escolas da localidade de Rio do Peixe (atual município de Carlos Gomes) chamar-se Oświata (Educação), ela era filiada à Sociedade Kultura. Estas sociedades de inspiração leiga surgiram na década de 1920 com o objetivo de qualificar a educação desenvolvida nas escolas polonesas, e que dominantemente estavam sob a responsabilidade de um professor leigo (SILVA; TRINDADE, 2017). Segundo Głuchowski, em janeiro de 1921 surgiu em Araucária, Paraná, o Distrito da Associação Profissional dos Professores das Escolas Polonesas Particulares e pretendia congregar todo o magistério polonês. Importante destacar que, nesse mesmo ano, na Colônia Erechim surge o Primeiro Distrito da União das Sociedades Educativas Polonesas "Kultura" do Rio Grande do Sul. E, "finalmente em março surge formalmente a União das Sociedades Educativas Polonesas Cultura" (GŁUCHOWSKI, 2005, p. 178).

Segundo Głuchowski, apesar da postura tolerante da Kultura, os padres acharam oportuno não assumir compromissos com ela e fundar uma organização educacional própria. "Assim surgiu 
em Curitiba, em abril de 1922, a União das Escolas Católicas Polonesas 'Oświata' (Educação), com o mesmíssimo programa da 'Kultura', apenas acrescentando a ele o ensino obrigatório da religião e enfatizando no seu nome a catolicidade" (GŁUCHOWSKI, 2005, p. 180).

As sociedades acima surgiram com o propósito de possibilitar a formação dos professores das escolas fundadas pelos imigrantes. E que, segundo Gardolinski, apresentavam a seguinte realidade:

\footnotetext{
O imigrante compreendeu finalmente que, nas circunstâncias e situações em que fora colocado - realmente difíceis - somente poderia vencer e melhorar as condições de vida das gerações vindouras através de um melhor nível cultural. Tratou, portanto, desde logo, de fundar sociedades e escolas que, embora revelassem as características étnicas de sua procedência, foram construídas por sua livre espontânea vontade. Procurou, em seguida, dotar essas modestas "forjas de ensino particular" com professores, muitas vezes, improvisados e até, em muitos casos, sem as necessárias aptidões para exercer o magistério. Contudo, eles estavam imbuídos de uma inesgotável dose de boa vontade. Deste modo, o elemento polonês, sem qualquer auxilio ou subvenção do Governo, nos albores daquela epopeia colonizadora - tomava inteira iniciativa e o controle sobre a vida de sua comunidade e, particularmente, sobre a instrução de seus filhos, numa terra absolutamente estranha e que, no entanto, em breve, se tornaria sua nova pátria (GARDOLINSKI, 1976, p. 150).
}

Para o ano de 1937, temos um número bem superior ao das treze escolas existentes em 1924. Não temos informações sobre a que Sociedade pertenciam as escolas: se à Kultura ou à Oświata. Também em 1937, a maior parte dos municípios listados nas tabelas número 5 e 6 não se constituía como unidades administrativas independentes de Erechim. Deduzimos, então, que a localidade onde se encontrava cada escola integra na atualidade os territórios destes municípios.

Tabela 5: Escolas confessionais na Colônia Erechim em 1937.

\begin{tabular}{|c|c|c|c|}
\hline Município & Unidade & Localidade & Professores \\
\hline C. Gomes & 1 & Sede & $\begin{array}{l}\text { Ir. Anastazja Pawlowska; Klaudia Malczewska } \\
\text { Ir. Wandaár Lbeagraac; Pkaawelo Awlosikzaa }\end{array}$ \\
\hline Áurea & 1 & Sede & Brodáwna \\
\hline Viadutos & 1 & Sede & Ir. Irena; Joana; Paulina; Teresa Kowalska \\
\hline Erechim & 1 & Sede & Pe. Marcin Kuszel \\
\hline Gaurama & 1 & Baliza & Católico Kolonko Naród \\
\hline
\end{tabular}

Fonte: Malikoski, 2014.

Pelas tabelas número 5 e 6, referentes ao ano de 1937, podemos observar que as escolas étnicas polonesas se distribuem pela Colônia Erechim. Seus professores são imigrantes ou descendentes de poloneses, e dominavam a língua materna.

Tabela 6: Escolas leigas na Colônia Erechim em 1937.

\begin{tabular}{lll}
\hline Município & \multicolumn{1}{c}{ Localidade } & Professores \\
\hline Erechim & Lageado dos Passarinhos & Fechada
\end{tabular}




Erechim
Erechim
Erechim
Erechim
Erechim
Erechim
Erechim
Erechim
Erechim
Erechim
Erechim
Aratiba
Barão de Cotegipe
Barão de Cotegipe
Getúlio Vargas
Getúlio Vargas
Getúlio Vargas
Getúlio Vargas
Getúlio Vargas
Getúlio Vargas
Getúlio Vargas
Gaurama
Gaurama
Gaurama
Gaurama
Gaurama
Áurea
Áurea
Áurea
Áurea
Áurea
Áurea
Centenário
Centenário
Centenário
Centenário
Ántenário
Aurea
Eura

Douradinho

Dourado Linha IV

Dourado Linha III

Boa Vista do Erechim

Tapir Linha II

Gramado

Lageado dos Porcos

Rio Tigre

Napoleão Bonaparte

Rio Caçador

Linha Tajui

Dourado Linha II

Cravo Linha II

Cravo Linha II

Kilometro 13

Getúlio Vargas

Barra do Rio dos Índios

Barra do Rio dos Índios

Rio dos Índios

Rio Paulo

Castilho

Secção III Dourado

Rio Suzanna

Paloma

Barro

Rio Branco

Lageado Veado

Rio Branco (Lombo)

Lageado Ligeiro

Treze de Maio

Linha VII, Treze de Maio

Vila Hortência

Treze de Maio

Chato Grande

Lageado Bocó

Lageado Valeriano

Lageado André

Centenário

Chato Gaúcho

Linha Mambira
Em organização

Felicia Grzejdak

Helena Lisowska

Boleslaw Brzoski

Jan Gozak

Józef Gorsk

Fechada

Andrzej Wypych

Longin Linderski

Franciszek Biedacha

Jan Górak

Piotr Lisowski

Boleslaw Brzosk

Franciszek Skowronski

Michal Kwiatkowski

Fechada

Szczepan Lewinski

Jósef Michlanski

Stefan Zbaralski

Fechada

Fechada

Zygmunt Woloszyn

Fechada

Paloma

B. Weclewski

Stefan Skorek

Szczepan Babínski

GenowefaWeclewski

Adam Kempka

Jan Sobczak

Boleslaw Wenclewski

Stefan Skorek

Henryk Stankiewicz

Antoni Pietras

Fechada

Jan Grzybowski

Maria Kurek

Jan Zygier

Franciszek Sztormowski

Franciszek Sitniewski

Paim Filho

Guabiroba

Stan Kulawczuk 
São João da Urtiga

Marcelino Ramos

Fonte: Malikoski, 2014.

A análise dos dados da Tabela 5 e da Tabela 6 evidencia que na região da Colônia Erechim as escolas leigas predominam. Isso nos leva a interpretar que, na sua quase totalidade, as escolas existentes antes da nacionalização do ensino eram de iniciativa de imigrantes. Pelos números e pela localização, pode-se dizer que, predominantemente nos centros, onde havia uma agregação populacional maior, as escolas polonesas estiveram a cargo das congregações religiosas. As mais distantes, dispersas no meio rural, embora não isentas da influência religiosa, não contavam com a estrutura e experiência direta das congregações.

Pode-se dizer que esta vai se constituir numa das razões da extinção e/ou desaparecimento de um grande número de escolas étnicas durante o período denominado e conhecido como nacionalização do ensino. Também se compreende por que as escolas da Região da Colônia Erechim estavam ligadas à Kultura e não à Oświata.

\section{As tensões e resistências na escola}

Buscamos apreender e analisar as tensões que perpassam o ambiente escolar de modo crescente no período do Estado Novo, com o objetivo de compreender o processo de conformação da escola "oficial" proposta/imposta aos imigrantes poloneses instalados na Colônia Erechim. Partimos do pressuposto de que as tensões são inerentes ao espaço escolar, que se caracteriza por disputas, conflitos e, portanto, resistências e tensões.

Destacamos que o objeto desta análise é aquela escola de imigrantes poloneses que vai se constituir a partir das políticas públicas de atenção aos grupos migratórios no Brasil, com o claro objetivo de nacionalização dos estrangeiros e seus costumes. Assim, pressupomos que as tensões se acentuam, na medida em que a "escola oficial" vii vai sendo materializada junto aos imigrantes poloneses.

Esta escola contrapõe-se àquela que se havia formado a partir da iniciativa dos próprios sujeitos, com objetivos de perpetuar a língua, a cultura e os hábitos trazidos do seu país de origem. Conflita-se com a "escola oficial" que vai impor-se aos imigrantes e seus filhos, especialmente a partir da Ditadura Vargas, pois "as escolas estão organizadas [...] para ensinar o conhecimento referente a quê, como e para quê, exigido pela nossa sociedade" (APPLE, 1989, p. 37).

Os processos imigratórios que caracterizaram a constituição da Região do Grande Erechim materializaram-se, na medida de seu assentamento, de forma mais ou menos homogênea. Assim que se foram estabelecendo, os imigrantes iniciaram um processo de organização e de produção da infraestrutura, que permitiria o provimento de alguns serviços considerados essenciais, ou seja, indispensáveis a sua sobrevivência. Temos observado que a constituição/construção da igreja, do 
clube e da escola constituíram as primeiras e importantes iniciativas de sua nova organização.

Esse processo de organização de escolas desenvolveu-se de maneira isolada durante as duas primeiras décadas do século XX. Para Malikoski (2014), as escolas eram mantidas exclusivamente pelos colonos, por meio de mensalidades pagas de acordo com condições previamente acertadas com os sócios (MALIKOSKI; LUCHESE, 2017, p. 98).

Aqui não nos deteremos em evidenciar qual destas três instituições nasce primeiro, até porque a história tem mostrado que, num momento inicial, estas três instituições se confundem. Isto significa que em muitas iniciativas a materialização de um destes espaços implica em, obrigatoriamente, instituir os demais.

Esses imigrantes procuravam construir espaços de ensino escolar para suas crianças. Os colonos sentiam a necessidade da escola para proporcionar o mínimo de ensino para seus filhos. No primeiro momento, as escolas funcionavam em espaços improvisados, como a casa de algum colono ou pequenas capelas. Nesses espaços, principalmente no caso das colônias rurais, era utilizada exclusivamente a língua polonesa (MALIKOSKI; LUCHESE, 2017, p. 95).

A organização da escola em questão neste estudo é aquela presente nos núcleos de imigração polonesa, na Região da Colônia Erechim, que, como vimos, teve uma grande expressão numérica. Desta forma, buscamos olhar a escola já presente no núcleo imigratório, nos anos de 1930-1940, e analisar as tensões que a perpassam, destacadamente os conflitos e manifestações que indicam a presença, no interior da escola, de preconceitos e resistências.

Analisamos inquéritos administrativos e cartas trocadas entre professores e autoridades educacionais municipais, referentes à escola. Estes inquéritos eram procedimentos instaurados pelo chefe do poder executivo, ou seja, o Prefeito Municipal, que constituía uma comissão, perante recebimento de denúncias por parte de algum membro da comunidade, para proceder à análise dos fatos denunciados. Estes registros encontrados nos documentos são produzidos a partir do momento em que as escolas passam a compor a agenda pública, ou seja, passam a ser atendidas pelas políticas públicas governamentais.

Assim, vai tornando-se corriqueira a ação e instauração de inquéritos direcionados a apurar as relações estabelecidas no interior da escola. Os inquéritos analisados dizem respeito às insatisfações da comunidade em relação ao que a escola faz, e estas eram atribuídas à figura do professor. Encontramos depoimentos como o de um pai de aluno, que diz: "A professora é boa, mas muito nervosa e acrescentou que não acha correto que ela mande os alunos descascar milho na hora das aulas". viii O que se destaca, no caso deste inquérito, são as insatisfações por parte da comunidade que questiona as ações desenvolvidas: do pai que estranha a imposição do trabalho 
manual e reivindica para seu filho relações menos duras.

Uma das facetas da ação governamental [..] medidas concretas de repressão.

Outra consistia em introjetar nessas populações um sentimento de brasilidade, criando um ambiente propício para isso. Segundo Coelho de Souza, para reverter esse quadro, o governo rio-grandense fizera "uma inteligente propaganda, principalmente junto aos escolares, de tudo quanto é nosso, assim despertando o amor das crianças pelo Brasil", seja por intermédio do magistério, da Liga de Defesa Nacional, da imprensa e por todos os meios hábeis da propaganda [...] Junto aos professores, o órgão de doutrinação criado fora a Revista do Ensino, engajada na campanha de "reconstrução nacional" e destinada prioritariamente aos professores primários. Todavia, a Revista não estampava as dificuldades e resistências que o professor enfrentava no seu dia a dia (NEUMANN, 2015, p. 215).

As relações entre professores e alunos acabam sendo simplificadas nos conflitos que se produzem. A reclamação do pai "que diz que, no dia anterior, seu filho de 12 anos de idade voltou à casa, dentro do horário escolar, dizendo que a professora o mandou embora porque a ele não daria mais aula". ${ }^{i x} \mathrm{Na}$ sequência, o mesmo pai afirma nunca ter tido qualquer tipo de desentendimento com a professora. Na medida em que o depoimento do pai de aluno avança, é possível perceber os motivos que desencadearam o conflito entre professora e aluno: a informação de que "indagou a outros alunos da mesma escola se era verdade que seu filho havia falado em língua estrangeira e todos responderam negativamente, dizendo que isso não acontecera na escola". ${ }^{x}$

O que precisamos ter presente é que as escolas dos imigrantes foram, inicialmente, sendo erigidas por eles mesmos e ensinavam em sua língua materna. O projeto de nacionalização das escolas impõe a língua portuguesa, pois, "para os ideólogos do nacionalismo, a língua era a alma da nação e o critério crucial da nacionalidade (NEUMANN, 2015, p. 205). Compreende-se que a figura do professor é central nas reclamações que se materializaram em inquéritos, pois este corporifica o projeto educativo/formativo estranho à língua e a cultura do imigrante.

\footnotetext{
Os pontos decisivos para determinar o fim do processo de ensinos nas escolas étnicas polonesas no país foram os que faziam referência às restrições impostas para o uso e o ensino da língua estrangeira e, para algumas escolas, a obrigação de possuir professores brasileiros natos. Constatamos que muitas escolas tiveram de fechar suas portas, porque o professor era imigrante ou vinha diretamente da Polônia para atuar no ensino (MALIKOSKI; KREUTZ, 2016, p. 75).
}

Os atritos entre pais e professores, resultantes do fazer cotidiano da escola por parte do professor, eram frequentes neste processo de "imposição da escola nacional". Assim: "o professor em sua defesa reclama que os pais querem ditar normas no trabalho... ele diz que tem por norma só ensinar em língua portuguesa e as matérias... obrigatórias de acordo com o regimento do ensino 
municipal de 24 de fevereiro de 1941" . ${ }^{\text {xi }}$ A defesa do professor se ampara também no Decreto-Lei n 406 da Presidência da República, de 4 de maio de 1938, que dispõe sobre o ingresso de estrangeiros:

\footnotetext{
Art. 85. Em todas as escolas rurais do país, o ensino de qualquer matéria será ministrado em português, sem prejuízo do eventual emprego do método direto no ensino das línguas vivas.

$\S 1^{\circ}$ As escolas a que se refere este artigo serão sempre regidas por brasileiros natos.

$\S 2^{\circ}$ Nelas não se ensinará idioma estrangeiro a menores de quatorze (14) anos.

$\S 3^{\circ}$ Os livros destinados ao ensino primário serão exclusivamente escritos em língua portuguesa.

$\S 4^{\circ}$ Nos programas do curso primário e secundário é obrigatório o ensino da história e da geografia do Brasil.

$\S 5^{\circ}$ Nas escolas para estrangeiros adultos serão ensinadas noções sobre as instituições políticas do país.

Art. 86. Nas zonas rurais do país não será permitida a publicação de livros, revistas ou jornais em línguas estrangeira, sem permissão do Conselho de Imigração e Colonização.

Art. 87. A publicação de quaisquer livros, folhetos, revistas, jornais e boletins em língua estrangeira fica sujeita à autorização e registro prévio no Ministério da Justiça (BRASIL, [2020]).
}

A partir deste Decreto-Lei, intensifica-se o processo de nacionalização do ensino e as escolas vão sendo encampadas pelo poder público e passam a responder por um projeto de educação centralizado a partir do Ministério da Educação e Saúde. Desde então, as escolas de iniciativas dos imigrantes passam a ser controladas, acompanhadas e o ensino deixa de ser ministrado na língua dos imigrantes.

Com o Estado Novo, um novo paradigma educacional foi implantado: o da assimilação. Todos os imigrantes deveriam aprender o português, expressar-se somente nessa língua e esquecer a sua cultura de origem. As escolas mantidas pelas diversas comunidades imigrantes são fechadas ou nacionalizadas, as reformas de ensino vão aos poucos implantando uma base curricular comum para todo o país (SANTOS; BAHIA; GOMES, 2016, p. 12).

Este novo paradigma passa a ser implantado, não sem muitas tensões e conflitos. O uso do idioma tem sido elemento de infindáveis atritos entre professores e alunos chegando à comunidade. São inúmeros os inquéritos como também são inúmeras as cartas dos professores às autoridades educacionais da Colônia Erechim - no caso, o subinspetor educacional - que relatam incidentes desencadeados pelo uso da língua polonesa na escola. A carta de março de 1943 deixa evidentes as consequências da determinação autoritária de negação da língua dos imigrantes no território brasileiro. Assim, após cumprimentar a autoridade, a carta inicia dizendo:

Hoje, isto é, dia 4 um dos alunos do $4^{\circ}$ ano de nome [...], filho do Sr. [...] 
começou falar em estrangeiro na aula. Repreendido guardou o ódio e no sair do Colégio, logo na porta, começou destratar e brigar com os alunos dizendo palavras desonestas, então eu fui perto dele para fazer paz e o menino disse um nome muito feio contra mim levantei então a mão para calar-lhe a boca e ele tinha uma mala de madeira na mão, querendo defender-se machucou-se no nariz e começou a correr o sangue. E eu dei levemente dois tapas nele que não dissesse estes nomes feios. O menino vai pra casa, conta o fato com mil mentiras, então o pai em vez de vir entender-se comigo, levou o menino de casa em casa mostrando sangue que ainda ficou na roupa caluniando-me como criminosa. ${ }^{\mathrm{xii}}$

A carta evidencia mais uma das inúmeras dificuldades pelas quais os imigrantes, neste caso os poloneses, foram submetidos durante o processo de acomodação e estabelecimento em solo brasileiro. A escola, por sua vez, externa que seu espaço não é um espaço neutro, mas sim de concretização de um projeto de sociedade e de desenvolvimento. E aos imigrantes, especialmente, no período ditatorial de Getúlio Vargas, são inúmeros os tensionamentos que daí decorrem. No caso em destaque, o de uso da língua de origem. Assim,

a repressão, via educação, foi a maneira mais efetiva e produtiva, a longo prazo, da campanha de nacionalização do governo de Getúlio Vargas, anunciada e efetivada a partir de 1937, com o Estado Novo. Por intermédio das escolas, atingiram-se as crianças, tanto nas áreas coloniais como urbanas (NEUMANN, 2015, p. 205).

Na mesma carta, a professora assim manifesta:

Eu aqui não posso compreender estes pais, pedem que castigasse e se uma vez a gente levanta a mão já estão caluniando. [...] Eu quero proceder bem e ter ordem e disciplina na minha aula, fazer os alunos conhecer o verdadeiro patriotismo, mas suportar tantos abusos e calunias do lado dos pais, não posso mais! ${ }^{\text {xiii }}$

Neste desabafo, a professora anuncia/denuncia o projeto educativo em implementação e sob sua responsabilidade: transformar os filhos dos imigrantes em verdadeiros patriotas.

\begin{abstract}
A ideia de "brasilidade" tornou-se um dos pilares que sustentavam o ideal de formar um povo integralmente homogêneo adaptado à "realidade brasileira". Dessa forma, romper com os "quistos étnicos" fazia parte dessa estratégia de integração, ou, como podemos dizer, de assimilação. As medidas mais violentas para romper os laços de solidariedade e identidade foram, sem dúvida, as proibições do ensino e uso de línguas estrangeiras, bem como a circulação de literatura em qualquer outro idioma que não o português. Dessa forma, a língua portuguesa passou a ser entendida como "cimento da brasilidade", adentrando nas organizações coletivas nas manifestações religiosas e, por fim, na esfera privada dos lares [...] (ZEN, 2010, p. 147).
\end{abstract}

A desqualificação tem sido um dos mecanismos presentes nas aulas que eram ministradas 
aos filhos dos imigrantes. O depoimento de um pai de aluno diz que "o professor não ensinou seus filhos e tratou de Russo e de burro e que durante o período que frequentaram a aula nada aprenderam, nada, que caso o professor continua não manda mais os filhos". ${ }^{\text {xiv }}$

Em outra carta, a professora relata o ocorrido e pede solução para o problema. Diz que só voltará a dar aulas quando a situação for resolvida. Em resposta, o relatório produzido pela comissão de inquérito apresenta o seguinte:

Devido a escassez do tempo não nos foi possível ouvir todos os sócios da mencionada aula. Entretanto dos cinco depoimentos que conseguimos obter, entre denunciantes e denunciados, concluímos que se trata de questiúnculas ou desavenças de pouca importância, salvo uma frase que ........dizem ter ouvido em 1938 do Padre [...], vigário de Floresta, que é de certa gravidade, pelo sentido impatriótico que encerra[...]. Afirma no entretanto que ouviu dizer que o Padre [...] disse que retirassem os "cabritos" (os não católicos romanos) e os brasileiros da escola tudo iria bem com a escola em menção. ${ }^{\mathrm{xV}}$

A conclusão apresentada não deixa dúvida quanto às intencionalidades do projeto de nacionalização das escolas e também torna evidentes as persistentes ações de resistência por parte dos poloneses.

\section{Considerações finais}

Buscamos uma retrospectiva histórica, fundamentada em documentos que evidenciam, não apenas dificuldades iniciais de chegada em um território desconhecido, mas, sobretudo, o registro de um processo de constituição de um novo sujeito social, que chega e é confrontado com as adversidades, mas se embrenha em construir seu espaço de existência. Pensamos que é desta forma que trouxemos neste texto, a partir da leitura dos documentos referentes à escola dos imigrantes poloneses, edificada na Colônia Erechim. Reflexão de uma construção conflituosa que se desenvolve a partir da nacionalização do ensino, decretada nos anos de 1937 a 1945, no Governo de Getúlio Vargas.

Observa-se claramente que a retirada do protagonismo dos imigrantes - no caso aqui em discussão, os Poloneses - vai desencadear relações de conflito e tensões no interior da escola e a partir dela. A comunidade, que até então detinha o poder de condução da sua escola, da afirmação da língua e outros elementos culturais, passa a estabelecer uma relação de confrontos e hostilidades para com o professor, representante do Estado brasileiro.

A escola pública oficial, instalada pelo governo, que vai se edificando no interior destes grupos étnicos, se materializa em meio a um processo de resistências, conflitos e tensionamentos. A brasilidade dos imigrantes e seus filhos vai sendo construída através da obrigatoriedade de que o ensino seja realizado na língua portuguesa e também pela seleção dos professores, que já não mais 
são de escolha e responsabilidade dos imigrantes.

\section{Referências}

APPLE, Michael W. Educação e poder. Porto Alegre: Artes Médicas, 1989.

BRASIL. Decreto-Lei $n^{o} 406$, de 4 de Maio de 1938. Dispõe sobre a entrada de estrangeiros no território nacional. Câmara dos Deputados, Atividade Legislativa, Legislação, [2020]. Disponível em: https://www2.camara.leg.br/legin/fed/declei/19301939/decreto-lei-406-4-maio-1938-348724-publicacaooriginal-1-pe.html. Acesso em: 20 jul. 2020.

GARDOLINSKI, Edmundo. Imigração e colonização polonesa. In: BECKER, Klaus (Org.). Enciclopédia Rio-Grandense, v. 5. Canoas: Regional, 1958, p. 3-114.

GARDOLINSKI, Edmundo. Escolas da Colonização Polonesa no Rio Grande do Sul. Porto Alegre: Escola Superior de Teologia São Lourenço de Brindes; Caxias do Sul/RS: Universidade de Caxias do Sul - UCS, 1976.

GŁUCHOWSKI, Kazimierz. Os poloneses no Brasil: subsídios para o problema da emigração polonesa no Brasil. Porto Alegre: Rodycz \& Ordakowski Editores, 2005.

ILLA FONT, Juarez Miguel. Serra do Erechim: tempos heróicos. Erechim/RS: Gráfica Carraro, 1983.

MALIKOSKI, Adriano. As escolas étnicas dos imigrantes poloneses no Rio Grande do Sul. Dissertação, Universidade de Caxias do Sul, 2014.

MALIKOSKI, Adriano; KREUTZ, Lúcio. Escolas entre imigrantes poloneses no Rio Grande do Sul e a Nacionalização do Ensino. Educação, Santa Maria/RS, v. 41, n. 1, p. 67-80, jan./abr. 2016.

MALIKOSKI, Adriano; LUCHESE, Terciane Ângela. O processo de organização de escolas étnicas polonesas no Rio Grande do Sul (1875-1939). Revista Brasileira de História da Educação, Maringá/PR, v. 17, n. 3 (46), p. 85-105, jul./set. 2017.

NEUMANN, Márcia Rosane. A nacionalização do ensino na colônia Neu-Württemberg, noroeste do Rio Grande do Sul, durante o Estado Novo (1937-1945). História Unicap, Recife, v. 2 , n. 4, jul./dez. 2015.

ROCHE, Jean. A Colonização Alemã e o Rio Grande do Sul. Porto Alegre: Editora Globo, 1969.

SANTOS, Mirian de Oliveira; BAHIA, Joana; GOMES, Charles. Aspectos socioeducativos dos processos migratórios. In: BAHIA, Joana; SANTOS, Miriam (Org.). Um olhar sobre as diferenças: a interface entre projetos educativos e migratórios [recurso 
eletrônico]. São Leopoldo/RS: Oikos, 2016, p. 7-18.

SILVA, Fabiana Regina; TRINDADE, Rhuan Targino Zaleski. Estado Novo, campanha de nacionalização e a restrição nos processos de sociabilidade étnica entre os polonobrasileiros no sul do Brasil: união das sociedades Oświata. Revista Semina, v. 16, n. 2, p. 1677-1001, 2017.

ZEN, Erick Reis Godliauskas. Imigração e revolução: lituanos, poloneses e russos sob vigilância do DEOPS. São Paulo: Editora da Universidade de São

Paulo/EDUSP/FAPESP, 2010.

Submetido em: 30/07/2020

Aprovado em: 26/08/2020

Publicado: 23/09/2020

\footnotetext{
i Professora Doutora em História pela Pontifícia Universidade Católica de Porto Alegre (PUC/RS). Professora associada da Universidade Federal da Fronteira Sul - Campus Erechim/RS.

ii Professora Doutora em Educação pela Universidade Federal do Rio Grande do Sul (UFRGS). Professora associada da Universidade Federal do Pampa (Unipampa) - Campus Jaguarão/RS.

iii Reimigrante é aquele que, já imigrado, se desloca para outra região, estado ou país.

iv De Severiano de Sousa e Almeida para Carlos Torres Gonçalves, em 4 de dezembro de 1912. Registro de correspondência oficial da Comissão de Terras e Colonização da Colônia Erechim do dia 13 de julho de 1911 até o dia 24 de março de 1914. Arquivo Particular de Antônio Pereira de Souza. Erechim/RS.

${ }^{v}$ Inquérito de 1941. Pasta Educação. Arquivo Histórico Municipal Juarez Miguel Illa Font - Secretaria de Cultura, Esporte e Turismo. Erechim/RS.

vi Ata de novembro de 1952, do Distrito de Carlos Gomes para o Prefeito Municipal de Erechim. Pasta Educação. Arquivo Histórico Municipal Juarez Miguel Illa Font - Secretaria de Cultura, Esporte e Turismo. Erechim/RS.

vii Estamos denominando "escola oficial" aquela que vai substituir a escola instituída/construída pelos imigrantes e passa a ser organizada e controlada pelo poder público.

viii Inquérito de 1938. Pasta Educação. Arquivo Histórico Municipal Juarez Miguel Illa Font - Secretaria de Cultura, Esporte e Turismo. Erechim/RS.

ix Inquérito de 1941. Pasta Educação. Arquivo Histórico Municipal Juarez Miguel Illa Font - Secretaria de Cultura, Esporte e Turismo. Erechim/RS.

${ }^{x}$ Idem, ibidem.

xi Carta. Pasta Educação. Arquivo Histórico Municipal Juarez Miguel Illa Font - Secretaria de Cultura, Esporte e Turismo. Erechim/RS.

xii Carta de março de 1943. Pasta Educação. Arquivo Histórico Municipal Juarez Miguel Illa Font Secretaria de Cultura, Esporte e Turismo. Erechim/RS.

xiii Idem, ibidem.

xiv Inquérito de 1941. Pasta Educação. Arquivo Histórico Municipal Juarez Miguel Illa Font - Secretaria de Cultura, Esporte e Turismo. Erechim/RS.

${ }^{x v}$ Relatório Comissão de Inquérito de 1941. Pasta Educação. Arquivo Histórico Municipal Juarez Miguel Illa Font - Secretaria de Cultura, Esporte e Turismo. Erechim/RS.
} 